\title{
Research and Practice of PAD Class Based on WeChat Platform in Medical Universities English Teaching
}

\author{
Yan Li, Xiaoqing Wen, Xianjiu Liao* \\ Youjiang Medical University for Nationalities, Baise, Guangxi \\ Email: 1xj2006910@163.com
}

How to cite this paper: Li, Y., Wen, X. Q. \& Liao, X. J. (2021). Research and Practice of PAD Class Based on WeChat Platform in Medical Universities English Teaching. Creative Education, 12, 1040-1046. https://doi.org/10.4236/ce.2021.125076

Received: March 28, 2021

Accepted: May 21, 2021

Published: May 24, 2021

Copyright $\odot 2021$ by author(s) and Scientific Research Publishing Inc. This work is licensed under the Creative Commons Attribution International License (CC BY 4.0).

http://creativecommons.org/licenses/by/4.0/

\begin{abstract}
Objective: To explore the impact of the PAD Class teaching mode on students' learning satisfaction and final comprehensive grades; Methods: Our students in higher vocational colleges from Class 1 of nursing profession enrolled in 2020 and 2019 were selected as the research objects, which were respectively experimental class and control class. PAD Class mode is given in the experimental class, while the traditional teaching mode in control class. After the course, the students were surveyed on questionnaires of their learning satisfaction in nine aspects, including acquisition of knowledge, and their final comprehensive grades were compared. Results: The learning satisfaction with PAD Class of the experimental class students is significantly higher than that of the control class. $86.27 \%$ of the students in the experimental class and $57.91 \%$ in the control class are satisfied. The final comprehensive grades of the experimental class are also significantly higher than that of the control class $(\mathrm{t}=6.301, P<0.001)$. Conclusion: As a teaching mode worthy of recognition and promotion, PAD Class can help to improve students' learning satisfaction and academic performance, tap students' ability of independent learning and acquiring knowledge, and lay a good foundation for the future lifelong learning.
\end{abstract}

\section{Keywords}

PAD Classes, Medical Universities, English Teaching, Learning Satisfaction, Learning Effect

\section{Introduction}

PAD Class is a new teaching mode proposed by Zhang Xuexin, a doctor of Prin- 
ceton University and a psychology professor of Fudan University. Its core idea is to divide the class time into two sections, half of which is given to the teachers and the other half to the students. The two sections intervals are one week, so that the students can learn independently, namely the PAD Class clearly divided into: Presentation, Assimilation and Discussion (Zhang, 2014). The advantage of PAD Class teaching mode is that it not only preserves the essence of traditional teaching, but also highlights the "student-oriented" teaching concept. The two are deeply integrated to help students learn and master knowledge better. The biggest innovation of PAD Class lies in the link of "Assimilation", which is regarded as a necessary part of learning, so that the concept of information-based independent learning of information technology may be spread throughout the whole learning and help students to establish correct learning habits. This paper tries to explore the influence of PAD Class on students' learning satisfaction and comprehensive academic performance by the application of PAD Class in higher vocational English teaching to provide some reference for educators.

\section{Research Objects and Methods}

\subsection{Research Objects}

Our students in higher vocational colleges from Class 1 of nursing profession enrolled in 2020 and Class 1 of nursing profession enrolled in 2019 were selected as the research objects, among which, Class 1 of nursing profession enrolled in 2020 was the experimental group (57 persons in total), and Class 1 of nursing profession enrolled in 2019 was the control group (55 persons in total). The courses of College English I of both groups are 46 hours, and the students of the two classes all use the third edition of New Horizon English Course 1 edited by Zheng Shutang and $\mathrm{Hu}$ Quansheng from Foreign Language Teaching and Research Press as the teaching material. The two groups of students can be compared with no difference in gender, age, and other basic conditions.

\subsection{Study Methodology}

PAD Class mode is given in the experimental class, which was divided into three parts: presentation, assimilation and discussion; traditional teaching mode is deployed in the control class, which was mainly taught by teachers. PAD Class is also based on the WeChat official account Duifene, which includes attendance, classroom questioning, online exercises, discussion area, homework, curriculum resources, teaching evaluation, grouping, voting and other functions to assist teachers in teaching and students in learning.

The first part of the PAD Class is presentation. The teacher explains and sorts out the structure, ideological value, key and difficult words and sentence patterns of the article to the students in the limited time, to leave the blank for the elaboration and make good demonstration and preparation for the assimilation of the students. The second part is assimilation. During the one-week interval, students independently study the relevant literature and materials with the ques- 
tions and tasks raised in presentation process, expand and improve the knowledge structure, and makes full preparations for the discussion stage. In order to better help students with independent learning, teachers upload relevant learning materials to the Duifene platform in advance to facilitate students' independent learning. At the same time, they can also actively participate in the discussion area of Duifene platform. The third part is discussion. Before the discussion, make sure that each student has the opportunity to participate in the discussion. When students tried to speak and express their opinions, they may exercise their language competence and communication ability. In other words, they have a good command of knowledge when they try to input and output what they learn.

\subsection{Effect Evaluation}

After the course, 38 students in the experimental class and the control class were surveyed on questionnaires of their learning satisfaction throughout the semester by random sampling. Likert grade 5 is used in the questionnaire, with 5 points indicating very satisfied and 1 point indicating very dissatisfied. It includes nine aspects of learning satisfaction, such as acquisition of knowledge, communication, team cooperation, independent learning, access to information, information technology application, innovative thinking, critical thinking and lifelong learning (see Table 1). At the same time, the final comprehensive grades of College English 1 of the experimental class and the control class were compared.

\subsection{Statistical Results}

SPSS 22.0 software was adopted in the data analysis. The enumeration data was represented in $\mathrm{n}(\%)$, and the measurement data was represented in $\left(\begin{array}{ll}\bar{X} & \pm \mathrm{s}\end{array}\right)$.

Table 1. Comparison of learning satisfaction between experimental group and control group ( $\mathrm{n}=76, \%)$.

\begin{tabular}{|c|c|c|c|c|c|c|}
\hline \multirow{2}{*}{ Investigation items } & \multicolumn{3}{|c|}{ Experimental group $(\mathrm{n}=38, \%)$} & \multicolumn{3}{|c|}{ Control group $(\mathrm{n}=38, \%)$} \\
\hline & Very satisfied & Satisfied & Satisfaction rate & Very satisfied & Satisfied & Satisfaction rate \\
\hline Ability in acquisition of knowledge & 15.79 & 73.68 & 89.47 & 7.89 & 60.53 & 68.42 \\
\hline Communication & 18.42 & 63.16 & 81.58 & 10.53 & 52.63 & 63.16 \\
\hline Team cooperation & 18.42 & 68.42 & 86.84 & 5.26 & 50.00 & 55.26 \\
\hline Independent learning & 21.05 & 73.68 & 94.73 & 10.53 & 55.26 & 65.79 \\
\hline Acquisition of information & 28.94 & 65.79 & 94.73 & 13.16 & 47.37 & 60.53 \\
\hline Information technology application & 26.32 & 63.16 & 89.48 & 10.53 & 47.53 & 58.06 \\
\hline Innovative thinking & 10.53 & 60.63 & 71.16 & 2.63 & 34.21 & 36.84 \\
\hline Critical thinking & 7.89 & 65.79 & 73.68 & 5.26 & 36.84 & 42.10 \\
\hline Lifelong learning & 26.32 & 68.42 & 94.74 & 15.79 & 55.26 & 71.05 \\
\hline Total average score & 19.30 & 66.97 & 86.27 & 9.06 & 48.84 & 57.91 \\
\hline
\end{tabular}




\section{Result}

\subsection{Evaluation on the Learning Satisfaction of the Experimental Group and Control Group}

It can be seen from Table 1 that the learning satisfaction of students in the experimental class to the PAD Class is significantly higher than that of students in the control group to the traditional teaching. $86.27 \%$ of the students in the experimental class are satisfied with the learning in PAD Class, 19.30\% of them are very satisfied, and $66.97 \%$ of them are satisfied. In the PAD Class of the experimental class, the highest satisfaction is the abilities of lifelong learning, independent learning and acquisition of information, accounting for $94.74 \%, 94.73 \%$ and $94.73 \%$ respectively. It is followed by the abilities of information technology application, knowledge mastery, team cooperation and communication, accounting for $89.48 \%, 89.47 \%, 86.84 \%$ and $81.58 \%$ respectively, and the last is the abilities of critical thinking and innovative thinking, accounting for $73.68 \%$ and $71.16 \%$ respectively. Because the proportions of dissatisfied and very dissatisfied students are nonexistent or very low, they are not listed separately.

In the control group, the satisfaction with the learning experience of traditional teaching mode is significantly lower than that of the experimental class with the Duifene class, with only $57.91 \%$ of the students expressing satisfaction, of which the abilities of critical thinking and innovative thinking are the least satisfied, accounting for $42.1 \%$ and $36.84 \%$ respectively. More than $70 \%$ of the students in the experimental class are satisfied, which shows that the teaching mode of PAD Class can better tap the students' abilities of innovation and critical thinking.

\subsection{Comparison of Final Comprehensive Grades between Experimental Group and Control Group}

It can be seen from Table 2 that there is a significant difference between the experimental class and the control class $(\mathrm{t}=6.301, P<0.001)$. The comprehensive grade of the experimental class is significantly higher than that of the control class. The average of the final comprehensive grade of the experimental class is 89.48 , and the standard deviation is 3.99 , while the average of the final comprehensive grade of the control class is 80.76 , and the standard deviation is 9.47 . $96.49 \%$ of the students in the experimental class score 80 points and above, while

Table 2. Comparison of final comprehensive grades between experimental group and control group.

\begin{tabular}{ccccccccc}
\hline Group & Number $\begin{array}{c}100-90 \\
\text { points }\end{array}$ & $\begin{array}{c}89-80 \\
\text { points }\end{array}$ & $\begin{array}{c}79-60 \\
\text { points }\end{array}$ & $\begin{array}{c}\text { Less } \\
\text { than } 59\end{array}$ & $\begin{array}{c}\text { Final comprehensive } \\
\text { grade }\end{array}$ & $t$ & $p$ \\
\hline $\begin{array}{c}\text { Experimental } \\
\text { group }\end{array}$ & 57 & $49.12 \%$ & $47.37 \%$ & $3.51 \%$ & $0.00 \%$ & $89.48 \pm 3.99$ & & \\
$\begin{array}{c}\text { Control group } \\
\text { Co. }\end{array}$ & 55 & $10.90 \%$ & $52.73 \%$ & $32.73 \%$ & $3.64 \%$ & $80.76 \pm 9.47$ & & $<0.001$ \\
\hline
\end{tabular}


only $63.63 \%$ of the students in the control class score 80 points and above, and $3.64 \%$ of the students in the control class fail.

\section{Discussion}

\subsection{PAD Class Is Conducive to Promoting Students' Independent Learning}

According to the survey, students believe that the PAD Class has significantly improved their lifelong learning ability (94.74\%), independent learning ability (94.73\%), ability in acquisition of information (94.73\%), ability of information technology application (89.48\%) and ability in acquisition of knowledge (89.47\%), which indicates that the PAD Class gives full play to the subjective ability of students' learning. Previous research found that the PAD Class has a certain promotion effect on students' independent learning ability and other aspects (Liao, Li, Huang, Li, Huang, Huang, \& Tang, 2020). During assimilation, students need to prepare materials for discussion. The tasks drive students to constantly screen, identify, and process effective information. In the continuous research and practice, their abilities of information acquisition and information technology application are fully trained and improved. In the information age with continual renewal of knowledge, the cultivation of independent learning ability and lifelong learning ability is very important. It can be seen that the PAD Class teaching mode can help students to establish correct learning habits and attitudes, and gain more positive learning methods.

\subsection{PAD Class Is Conducive to Promoting Team Cooperation and Communication}

In the survey, the team cooperation ability (86.84\%) and communication ability (81.58\%) of the experimental class students are significantly improved compared with the control class students. Shi Mengxi found in the study that the team cooperation of the students in PAD Class has a great effect on performance promotion (Shi, 2017). Compared with the traditional classroom of the control class, the experimental class with PAD Class not only retains the advantages of traditional teaching, but also embodies the teaching concept of "student-oriented". During the discussion of PAD Class, the team cooperation spirit and communication ability of students are fully exploited. Taking Unit 5 of $\mathrm{NeW}$ Horizon English Course 1 as an example, the theme of this unit is sports, in which Section A is about the tennis star $\mathrm{Li} \mathrm{Na}$, and Section B is about the basketball star Michael Jordan. At just over 300 words per article, it's not enough to get a full picture of the two superstars. The PAD Class teaching mode helps students learn about $\mathrm{Li} \mathrm{Na}$ and Jordan not only from the perspective of the author, but also through their own access to information. More importantly, in the discussion and sharing, they can know Li Na and Jordan from each perspective of other students. PAD Class obviously builds an efficient learning platform for students. During the discussion, the students collaborate to share more interest- 
ing and meaningful stories about $\mathrm{Li} \mathrm{Na}$ and Jordan, which improve their abilities of team cooperation and communication.

\subsection{PAD Class Is Conducive to Promoting Innovative Thinking and Critical Thinking}

The cultivation of innovation and critical thinking is the foundation of national independent development, and also an important part of the core literacy of education (Huang, Zhang, Mo, Zhang, Li, \& Lin, 2021). The survey found that the satisfaction of the experimental class students on these two abilities is significantly higher than that of the control class, which benefits from the assimilation and discussion. During assimilation, students can get a deeper understanding through the collation and thinking of knowledge, and at the same time, their innovative thinking is well exercised through day after day thinking. During discussion, the students share and discuss their own views with collision and integration. In this process, they not only improve their cognition of things, but also imperceptibly learn how to communicate and exchange and treat each problem objectively and critically. Ma Luyan et al. also believe that PAD Class is conducive to cultivating college students' innovative thinking ability and critical thinking (Ma, 2020). It can be seen that PAD Class creates a good environment for the improvement of innovative thinking and critical thinking ability.

\subsection{PAD Class Is Conducive to Promoting Students' Comprehensive Academic Performance}

In the evaluation of the final comprehensive grade, the experimental class with the PAD Class teaching mode has a significantly higher grade than the control class, with the score above 90 accounting for $49.12 \%$, and the score above 80 accounting for $47.37 \%$. The students in the experimental class have achieved a good final score. The research of Li Mengduan and Zhang Linyu also found that PAD Class has a positive impact on students' English learning performance (Li \& Zhang, 2021). It can be seen that the teaching mode of PAD Class is of great help to students' learning. It not only cultivates students' good habit of independent learning, but also helps students construct deep and meaningful learning, fully mobilizes students' subjective ability of learning, and realizes learning happiness and healthy growth in a pleasant learning atmosphere.

\section{Conclusion}

PAD Class teaching is more suitable for the learning thinking mode of Chinese students. Through PAD Class teaching, students' learning satisfaction can be improved, such as lifelong learning habit, independent learning ability and knowledge acquisition ability, and it is also conducive to the cultivation of team cooperation spirit and communication ability. It also has a certain reference value for the development of innovative thinking ability and critical thinking ability, so it can be seen that PAD Class teaching mode is worthy of affirmation 
and promotion.

\section{Fund Program}

2018 Guangxi Vocational Education Teaching Reform Research Project + Research and Practice of PAD Class based on WeChat Platform in Higher Vocational Public English Teaching in Minority Areas + (GXGZJG2018B161).

\section{Conflicts of Interest}

The authors declare no conflicts of interest regarding the publication of this paper.

\section{References}

Huang, S. L., Zhang, Y., Mo, L., Zhang, W. X., Li, H., \& Lin, C. D. (2021). Pivotal Indicators of Innovative Competency in the Frame of Key Competency. Journal of Beijing Normal University (Social Sciences), 02, 27-36.

Li, M. D., \& Zhang, L. Y. (2021). A Mixed-method Study of PAD Teaching Mode-based College English Teaching. Journal of Changchun Normal University, 40, 182-185.

Liao, X. J., Li, Y., Huang, Q. C., Li, Z. Z., Huang, S. Y., Huang, X. F., \& Tang, Q. L. (2020). Research and Practice in Teaching of Analytical Chemistry Based on Duifene PAD Class and Formative Evaluation. Creative Education, 11, 1541-1551. https://doi.org/10.4236/ce.2020.118112

Ma, L. Y. (2020). Analysis of Cultivating College Students' Innovative Ability by PAD Class. Survey of Education, 9, 137-140.

Shi, M. X. (2017). Reflections on the Improvement of College Students' Comprehensive Quality in PAD Class. Knowledge Library, 6, 60-61.

Zhang, X. X. (2014). PAD Class: A New Attempt in University Teaching Reform. Fudan Education Forum, 12, 5-10. 